\title{
The Gendering of Objectivity and Resistance to Feminist Knowledge
}

\section{An Interview with Anne Fausto-Sterling and Julie Nelson}

\author{
by Lea Skewes, Post-Doctoral Researcher, Department of Political Science, \\ Arhus University \& Mads Ananda Lodahl, author and speaker
}

\section{Introduction}

What is the difference between having an opinion on gender and having knowledge about gender? Can both laypeople and scientists tell opinion and knowledge apart? Can we successfully separate science from cultural assumptions about gender? These were some of the questions we invited Anne Fausto-Sterling (who is a Professor Emerita of Biology at Brown University) and Julie Nelson (who is a Professor of Economics at University of Massachusetts Boston) to discuss at the Women's Museum in Aarhus in March 2015. We chose these two professors because they are both famous feminist icons who have chosen to raise important discussions about gendering in science within their disciplines of biology and economics, respectively. ${ }^{1}$

Some of the highlights from our discussion center on how the discipline of science and the concept of objectivity have been fundamentally gendered from the beginning, with white European men being understood as the ideal scientists, while women and people of color have been disqualified from legitimate knowledge production simply because of their gender or skin color.
We also cover the topic of backlash against feminist progress and how two feminist steps forward often lead to one step back. Here, Fausto-Sterling offers the example of the birth control debates in the US. She explains that the right to birth control was won many years ago but is currently being challenged again; a challenge which, after our dialogue, has in fact been carried out to the extreme under the Trump presidency, where women's abortion rights have suffered immense setbacks. Nelson also underlines that feminist progress is not necessarily linear. She offers the example of electing the first Black president of the US, Barack Obama, which to some was interpreted as the end of racism, only to then bear witness to the local riot of Ferguson in 2014 after the Black man Michael Brown was shot and killed by police. Since our dialogue, the Black Lives Matter movement, which was born out of Ferguson, grew to become a national riot in 2020 during the corona pandemic when yet another Black man, George Floyd, was suffocated by a police officer. This captures the fact that struggles for equality and justice - the old as well as the new - are as pervasive as ever, and that we need to understand these struggles if we want to understand the age 
in which we live. We hope that you can find some inspiration for your equality and justice struggles in this interview.

\section{Positioning Oneself and Feminist Objectivity}

LODAHL: "I will start by introducing myself in order to explain who I am and why I have been invited to carry out this interview. About 10 years ago, I was so fed up with homophobia that I got together with some friends and formed a revolutionary, militant, underground group. We worked as an affinity group, an artist collective, a queer street gang, and a political cell. We called ourselves Queer Jihad and considered ourselves part of a queer movement. We taught self-defense to queer kids and painted graffiti. We also organized parties, film screenings, and lectures and wrote on the topic. Basically, we just wanted to run into what we called the straight world order and put things on fire! We were angry. Two years into this project, Trine Munk, another co-founder of the group, told me she had found out that there was something called queer theory and feminist theory - which was something they taught at the university. None of us had heard about this before. We started studying queer theory and feminist theory on our own, and while I had had the anger, the political involvement, and the motivation before, I now got a deeper understanding of the political situation as well as better arguments to promote my cause. So, queer and feminist theory functioned like gasoline to the fire that was already burning!"

"Today, we have two people with us who have been teaching some of these things since before I was born. So, I feel very privileged and honored to be able to engage in this dialogue. Let us start with you Julie Nelson. You have been part of a group of people who invented something called feminist economics in the 90s. I would like you to tell me what the main question you have been asking in your research has been? What has been the main topic you have been trying to investigate in your research, and what have you found?"
NELSON: "The main thing that I have been working on is the discipline of economics itself and how the ways we think about the economy is affected by beliefs about gender. When I started working in economics, thinking about there being two genders was an improvement over what was there before because it was assumed that there was just one human experience and that was the male experience. Yes, there were all these other people - women - but they were not considered to do anything interesting or valuable, so as economists, we assumed that we did not need to pay attention to them."

LODAHL: "But what is the problem with that in the discipline of economics?"

NELSON: "For example, there is a total neglect of everything that women traditionally did in households. So, when women left what they had traditionally been doing at home and got jobs, this just looked like there was added productivity. There was no account of the loss of things that had been done before because the work at home had not been included in the model in the first place. In this way, there was no account of the general welfare of people; only what had been done in a masculine market because that was all which would be counted. This revealed that we had all these gender biases built into the economic models about what actually contributes to human welfare."

"I have also worked on some more nerdish things that have to do with how economists go about their studies - that there is a big elevation of quantitative research and no respect for more qualitative research - which also fits into a gender binary with the quantitative research being perceived as more masculine while the qualitative research is perceived as more feminine. And let me say, I do not think the answer is to flip the coin on the other side and say, 'Math is pure evil - we have to do purely qualitative research instead.' But we are limiting ourselves by only using half of the methods we could be using to investigate the world when we buy into that gendered quantitative-versus-qualitative binary." 
LODAHL: "Why is this important? What does it give us to include women in the models of economics?"

NELSON: "In my own case, I have been interested in why we think of the economy and commerce as a realm where it is okay to be self-interested, rational, and even opportunistic - why this is even expected of people working in business whereas we tend to still think of our families in terms of care and interrelations. Why do we have these binary expectations? I think we have lost an older idea of business and commerce as an area which was also about care and responsibility. But by thinking of the economy as this kind of mechanical and mathematical realm which sides with masculine self-interest and rationality and conflicts with interpersonal relations, we have severely hampered how we think about the ways in which money and the markets actually do work."

LODAHL: "So, masculine qualities like self-interest or profit maximization versus feminist qualities of care and interpersonal relations exist in both private realms and work spaces?"

NELSON: "Yes, I think they actually do exist in both realms, but we have gotten into the habit of thinking about them along this gender binary that bifurcates our perceptions so that home is only about care and work places are only about self-interest. And the implicit assumption is that we cannot raise the bar to include care in the workplace."

LODAHL: "Okay, so you think that both realms might benefit from opening up these narrow binary perspectives?"

\section{NELSON: "Yes exactly!"}

LODAHL: "Anne Fausto-Sterling, you have been working in biology and gender, so I am going to ask you the same question: Can you tell us about the main question that you have been trying to investigate throughout your career and what your research findings were?"
FAUSTO-STERLING: "I think that it has changed a bit over time as the political circumstances have changed. I got involved in these issues in the late 1970 s to early 1980 s as an activist in the feminist movement. I was part of the feminist movement, which was arguing for greater political participation and economic rights for women. We were pointing out things like the fact that women's work in the home has value even though it is unpaid - these kinds of topics that were part of the second wave of feminism. One of the responses we often heard from the opposition was couched in arguments about biology - that women could not do certain types of work because they were not strong enough, smart enough, or aggressive enough. A very famous example of this biological essentialism was put forward by Hubert Humphrey, who was the vice president of the US at that point. This was shortly after the Cuban missile crisis when Kennedy and Khrushchev were considering dropping nuclear bombs and starting WorId War III. What Humphrey said was that if there had been a woman as president at the time, she would not have had the emotional stability to face Khrushchev and make him back down. In other words, he assumed that we would have ended up with WW III if we had had a female president."

"I was hearing arguments like that. I was hearing arguments about how men get ahead because they are more aggressive than women. I was a young biologist at that point. I had just completed my $\mathrm{PhD}$, and until then I had primarily worked on fruit flies - I did not know much about human biology. But people would stand up in meetings and cite these experiments on the link between testosterone and aggression in rats. And people would turn to me and say; 'Well you are a biologist - is that true?' And I was like, 'I do not know!' Motivated by this, the first feminist intervention I made was to write a book called Myths of Gender - Biological Theories about Men and Women, in which I looked at each of these myths - as I came to conclude they were - about biological theories. I looked at each of these theories in detail using my skills as a biologist to analyze the work and then explain to a bigger audience what the work was and, more importantly, what it was 
not. But making that book raised questions for me because what was astounding to me was that the authors of this work were major biologists of their time. Take for example, Charles Darwin or the people who founded the field of psychology in the United States. It was researchers like Thorndike, who was the author of a dictionary we all grew up with back then. These were the best scientists of their time, and they received rewards for doing this work even though contemporary biologists would look back at it and say, 'Oh that is just bad science!' And I would say, 'Yes, it is bad science, but it was done by the best scientists at the time!"'

"So, I left that book needing to understand how that could be. How could the best science of the time get it so wrong? How could science - which was supposed to be objective and have no point of view - have such a strongly gendered point of view? How could the best minds of the time have this gendered point of view and not even know it and even sometimes actively deny their point of view? So, the next book I wrote tried to make sense of how culture becomes an ingrained part of science - in this case the culture of sexism. How does sexism become part of the fabric of science without people even knowing it? In order to answer that question, I turned to a different intellectual movement called Feminist Science and Technology Studies (Feminist STS), which I am still very actively engaged in. And then I wrote my second book, Sexing the Body - Biology and the Social Construction of Gender, in which I tried to show how cultural knowledge of gender actually becomes folded into what looks like objective knowledge".

LODAHL: "This is interesting because we often have this perception of science as producing objective knowledge in contrast to subjective opinion. But what you are describing is how cultural opinions shaped the knowledge that was produced - without the researcher even being aware of it. In this way, you are blurring the traditional distinction between knowledge and opinion."

NELSON: "That distinction between knowledge and opinion is interesting because when we started putting the word 'feminist' and 'economi$\mathrm{cs}^{\prime}$ together in the same sentence, most economists immediately rejected it as too subjective and political. They assumed that economists were producing neutral and objective knowledge and feminists were trying to politicize it. The assumption was that economics had objective knowledge, and we were adding a bias which was not there beforehand. My first individual book, which is called Feminism, Objectivity and Economics, points out that the feminist critique is not that economics is too objective but, rather, that it is not objective enough! You can look at some of the early work on economics and the household, and you can read right out of it what the economists' gender assumptions were. For instance, the models were 'proving' that it made sense for women to specialize in staying at home because they earned less than a man on the market. This was used to rationalize that men should be the only ones on the market. Nobody asked, 'well why is it that we get that wage differential on the market to begin with?' We get it because women specialize in the home, and that gives them less experience on the market. In this way, it was this circular argument which was accepted within the economist profession as the best objective explanation. This just shows that it is very difficult making a distinction between opinion and knowledge. Separating opinion and knowledge is very shady in practice. I am a real social scientist at heart. I want to see what knowledge data can bring. In my recent work, I have been exploring how behavioral economists have been reproducing gender stereotypes by treating their data unprofessionally. They have been reproducing ideas about how women are more risk averse than men, and it is simply not there in the data. I really strive to look at what the data is telling me. And I am sure that someone coming 20 years after me can look back at my work and say, 'She did not notice that she had this assumption'. And they would be right because it is very difficult to be aware of all of your assumptions in your work, but that does not mean that we cannot try. This is why, it is so important that we do not hold onto a definition of objectivity which focuses on whether 
the individual follows some particular method or mathematical reasoning. Instead, our definition of objectivity should focus on whether our work stand up to larger and more diverse communities? It should be the wider community that checks whether we are being objective, not an abstract method carried out by one person in isolation."

FAUSTO-STERLING: "Feminist STS and feminist approaches to science in general included philosophers of science and historians of science right from the start. We struggled with this idea of objectivity because it has been so intimately linked to science. So, we spent a lot of time thinking about what was meant by objectivity. There is some wonderful historical work on the rise of the idea of objectivity. There is a classic book in science studies by Shapin and Schaffer called Leviathan and the Air-Pump. The book is about Thomas Hobbes and Thomas Boyle. Boyle is often seen as the person who originated the scientific method. He did all his early work on gas laws and vacuums. In the 15th century, there was a huge scientific debate about what a vacuum was: Was it the absence of air, or was it something else? So, he did all of these experiments using a vacuum pump. For instance, he would place a bird inside a glass, and then he would pump out the air and show that the bird would die. But the way in which it was established as 'objective' science was by having a group of people observe the experiment. The observation by others was what made it become an 'objective' fact. These people - the observers - who in the language of the time were called modest witnesses were necessary for the scientific process. Anyone familiar with Donna Haraway's work will know that phrase from her title Modest_Witnesses. But the point is that women were explicitly excluded from being modest witnesses - they were excluded from the notion of objectivity because they got upset when the bird died. In this way, they interfered in the process of science by having a viewpoint about killing birds. Therefore, it was concluded that they could not be relied upon to validate something as a fact. This means that the exclusion of women from science and placing women in opposition to the notion of objectivity was an ingrained part of science from the dawn of modern science. It was an explicit exclusion of women. It was not an accidental exclusion. So, when people began researching the history of modern science and the history of the idea of objectivity, it became clear that gender was embedded in the understanding of both science and objectivity from the very beginning. Even the use of the word objectivity was a weapon against the inclusion of women. Therefore, the question for feminist researchers became how to counter that use of the word so as to not exclude women. And of course, women were not the only ones who could not be modest witnesses - there were many others who fell short of objectivity. Only white middle-aged men could validate a fact."

"Because of the explicit and intentional exclusion of women from the production of scientific facts, there was a whole intellectual movement in the 70s, mostly from feminist philosophers who was writing about objectivity. They were trying to figure out how to reclaim objectivity in a way that made it more inclusive of different points of view. This is what became standpoint theory, and it was part of a movement to reclaim objectivity and to reclaim who could make facts. This introduced the idea that facts that covered more of the world, as seen by a wider diversity of people, were considered better facts than facts that just covered the middle class nobility in England in the 15th century."

"This explicit gendering of science, and in particular the concept of objectivity, has shaped large parts of my career. But now I have made a shift in my career where I have started to focus on how we have conversations about sex and gender and also race without getting into a language of nature versus nurture. Now, I want to explore how bodies come into being; how bodies acquire what we think of as gender; how bodies become racialized. And for that, I have turned to the work which I am currently doing. I have returned to empirical work, and I am trying to use a dynamic approach to human development to understand how we become who we are. I am looking at development from before birth and through the 
entire life cycle. I am looking at the dynamic between the biology and culture, which I think are not separable. What I am arguing is that culture actually changes nature and vice versa. So, that is where I am at now."

LODAHL: "So, the biology of the brain for example can be changed by culture - how?"

FAUSTO-STERLING: "It is quite well-established in neuroscience that when infants are born they have relatively few interconnections between their neurons. Their development does not primarily consist of them growing new nerve cells but, rather, of them developing increased interconnectivity, which is the branching of connections between each nerve cell. This interconnectivity between the nerve cells grows enormously in the first few months of development and throughout the first five years of life. So, you start out with neuronal networks that look like a set of small, almost dead bushes because they have no leaves in the beginning, and then, by the end of the five years, you have this enormous brain with very complex trees of interconnectedness with lots of branches and leaves. And this increase in complexity is what neuroscientists call experience dependent. So, if you think of a baby, it is like a little sensory sponge. Hearing, seeing, and experiencing touch, it uses all the five senses to take in the world. The senses function as a constant input for the little baby. If you have an infant who has been deprived of sensory input, for instance in an orphanage, its brain does not develop properly. And it is very clear that all of this development is driven by the inputs. So, the idea that you are born with a fixed brain has long been refuted. No one with knowledge of neuroscience believes that today. So, for me the question is what all those sensory inputs are doing. How are they shaping the brain? How are they shaping the brain from the very beginning? Because their shape will affect behavior as the infant grows."

\section{Choosing the Right Metaphors to Capture Gender Differences}

LODAHL: "If development of the brain is experience dependent is there then an essential difference between men and women? Because that does seem to be one of the persistent myths - that there are important biological differences that will manifest themselves no matter what stimuli people are exposed to. Last night we talked about the book Men Are from Mars, Women Are from Venus (1992) by author and relationship counselor John Grey. I do not know if anyone in the audience has read it. I read it. It is funny and really stupid. Basically, what it argues is that there are these essential difference between men and women, and they will manifest themselves no matter what. So, as you say, we already know scientifically that this is not necessarily the case so why do people want to believe this narrative?"

NELSON: "Economists have recently started looking at how people actually behave instead of exploring how they would logically behave in a formal model. This is called behavioral economics, and it includes some aspects of psychology. Some of my more recent work is looking at our beliefs about gender versus what we actually do in choosing and enacting our own gender roles. It turns out that this binary belief about what is masculine and what is feminine is important in structuring our brains, but it is something that we make up in our brains rather than essences that are out there. We use it all the time, so it is very important for how we sort things. Let us illustrate this with an example: cats and dogs. Do people have gendered associations? Generally, in European and American cultures, dogs are considered more masculine. We can get even more abstract: odd and even numbers. Odd numbers are sometimes considered more masculine and even numbers more feminine. Pythagoreans thought that odd numbers were more masculine because they could not be penetrated by the number two. So, our brain definitely uses these binaries. And some psychological studies have looked at this. There tends to be a lot of agreement within a culture on what a 
stereotypical man is and what a stereotypical woman is. However, when you start asking people what they are then you get what psychologists call mosaicism. Rather than one big uniform tile, it is a multitude of different colored tiles. So, if you are a man and you like art and music, we have already picked a couple of things out of that feminine category. If you are a woman who is heterosexual, but you like football or controlling your own money, then you are picking things out of the masculine category. And if you look at things which behavioral economists are interested in like risk aversion, competition, and altruism, then we tend to think about it in this Mars-versus-Venus kind of way. It is a metaphor that leads us to think in extreme differences. I think we should use a different metaphor - and this is a US-based one, so you can create your own one if you like. The alternative metaphor which I suggest is that men are from North Dakota and women are from South Dakota (which are two neighboring states in the US). It is not a metaphor that leads you to expect extreme differences. There are gender differences that are detectable, but they are not this radical difference in behavior - there is a whole lot of overlap. So, when we talk about gender differences, we should talk about both gender differences and similarities. Yes, there are some differences on average on behaviors, but there is also an enormous amount of overlap and similarity - and that gets lost with the Marsversus-Venus metaphor."

\section{Changing Minds by Changing Discourse}

LODAHL: "If something as simple as the choice of a metaphor can feed into biased perceptions of both gender and science, then how should we strive to get this nuanced perspective out to the common public?"

NELSON: "There are at least two sides to that. The most important thing is that scientists themselves should not be putting the wrong facts out there! For instance, economists are often extremely naïve on the issues of gender and have put out these statements about women being more altruistic and more risk averse even though their data does not back this up. Many economists really do not understand the gendered problems ingrained in these claims at all, maybe because some of these economists believe that there are essential differences between men and women at a Mars-versus-Venus level. Therefore, we sometimes end up with scientific articles that read as if the gender-stereotypical conclusion was written before they collected the data. There is so little evidence there, and yet they conclude with these broad-sweeping, gender-essential statements. I am trying to convince my fellow economists to do research and make claims only based on their research data - I know it is revolutionary."

"The other challenge when communicating about science to the common public is the translation into media. This requires the journalists to be responsible in their reporting. I have personally been trying to experiment a little with conveying statistics in ways that are more approachable. For example, some economists say that women are more risk averse than men, but what would that mean if you selected one man and one woman at random? What is the chance that the woman would be more risk averse than the man? If there was no gender difference, the chance would be $50 / 50$. The difference they do find is closer to $56 / 44$. We are not talking about $100 / 0$ or $90 / 10$; we are talking about this small difference, and we should remember to be explicit about that."

FAUSTO-STERLING: "Keep in mind that we are living in a remarkable period in terms of social media, which everyone in this room has access to. I mean, you can write something that counters the wrong messages and put it up on a blog. You can tweet about it or devote a homepage to the myths of economics or any particular area you specialize in. It is no longer true that you have to hope that some newspaper editor will come and interview you. The journalists and editors no longer hold all the power in terms of getting different ideas out to the public. Everyone in this room could have a blog about gender and once a month put up a post and develop an audience. You can do it with 
WordPress, Facebook, or if you are less longwinded like I am, you can use Twitter. It is a little bit like the Wild West out there, but it is an opportunity to change the discourses for the better."

LODAHL: "Are you optimistic that we can change the discourse for the better around both science and gender? And what would it take for us to break through the gender stereotypes?"

FAUSTO-STERLING: "Sometimes scientific discourse becomes monopolized, and it can be hard to break through with alternative messages. I spent some time thinking about how certain academics gain the majority voice in a field. A perfect example of this is John Money, who was a sexologist from the US. He worked on intersex topics in the 50s, 60s, and 70s, and he came to control the discourse about what could be said within this field. You could not get something published if Money did not agree because he was on every editorial board, and he published everywhere. For a long time, he became the only voice on the topic. So, one of the things about changing discourse is that you do have to be repetitive. You cannot just go out there once and say, 'No, it is not this way, it is this way.' You have to say that again and again. For instance, I get a lot of phone calls from reporters who want me to comment on a new paper that is out which says it is $3 \%$ genetic and $97 \%$ culture. And the first thing that I do is that I refuse to engage with that language. Then I try to explain a more dynamic view. But I refuse to engage with the nature-versus-nurture construct of the question. That is the first thing you can do. The other thing is to try to come up with better ways of saying it - like Julie's example with the metaphor of North Dakota versus South Dakota. It is not enough to say that the current approach is wrong; you also have to have a lot of good sound bites showing a better way to think about it. Changing the actual language of discourse at a broad cultural level is a slow process. It requires persistence. You have to keep at it in many different venues. When people come to you with the nature-versus-nurture construct, you have to avoid engaging with them and, instead, insist that they leave that language at the doorstep and consider this other, more dynamic language."

NELSON: "I think you should also keep in mind that you can use terminology strategically - even if the terminology is sometimes limiting. For instance, in the work I have done in critiquing behavioral economics, I am using a male-female binary because that is what they use in this research. Do I believe that there is a simple male-female binary? No! But if I were to spend pages explaining this at the beginning of the research, they would never get to the critique. There are times when you do need to stop the discourse at the door and say, 'You know what? I am not going to deal with the nature-versus-nurture or the male-female binary.' But there are also times when you have to use the categories strategically - and that is a judgement call. I disagree with people who believe that you can never use the tools of the master. I think that, sometimes, it can be strategically wise to do so if you want people to engage with your critique."

\section{Power Dynamics and Backlash}

LODAHL: "But if people think in these extremes and they use these misguided metaphors, how do we then achieve change? Do you think we first need to understand why people are eager to believe in this binary?"

NELSON: "I can think of two reasons that should both be considered. 1) Are there issues of power? Is it in the interest of some people in power to maintain power? Because if you get some advantages from believing that men are more competent in the workplace, then you probably want to continue spreading that belief. We should not neglect the power aspect. 2) You can also be psychologically motivated to buy into the binary just because it is simple and easy to think within that framework. It can give a certain kind of confidence or safety to think, 'Oh, I am a woman; I do not have to be financially responsible because somebody else should take care of me.' I find that to be a horrible attitude, but you have to admit that it can have some appeal 
if you do not want to take on that kind of responsibility for yourself. It might reflect a fairly suppressive mindset, but it might feel safer because it is familiar. These kinds of dynamics might feed into the preservation of these kinds of dichotomies."

FAUSTO-STERLING: "I think it is important to mention that even though there is resistance to change things have changed a great deal since the new wave feminism of the late 1960s! There have been great changes, and they have become integrated in the legal system. I mean, as a result of new wave feminism, discrimination has been made illegal! Women are entitled to the same pay for the same work - that is now in the law - even though we still have not achieved it in practice. There has been a whole series of changes around questions of violence against women. There are rules against sexual harassment in the workplace that did not exist before. The laws around rape and sexual violence have improved. There is even a whole infrastructure around the violence against women that did not exist before. There are women's shelters. There is counseling. There are people who are experts within these fields now. And that change has come because of political activism! This change came exactly because we had a mass movement. This mass movement changed people's minds. It is not that this kind of attitude has gone. It takes generations to change the deeply embedded cultural ideas about gender. I think the time scale that I had in mind as a young feminist was completely off. I thought 10 years would be enough to solve the problems, but now I realize that it is going to be more like five generations. But during that time, you can observe the change. So, I think when we worry about resistance to change, we also need to remember that there has in fact been a lot of change for the better."

LODAHL: "I can relate to that. When I started getting involved in fighting hate crimes, I gave myself six months to solve it. By the end of that time, I promised myself, there would be no more hate crimes in Denmark. Of course, I later realized that this was unrealistic. A bit silly even. Sometimes when talking about political struggles, but maybe especially in relation to gay rights struggles, I have heard people use the phrase 'We are almost there' as in 'We have come a long way - we still have a way to go, but we are almost there.' But will we ever get 'there'? What will it be like 'there'? And how long can we stay 'there'? Where will we go afterwards?"

FAUSTO-STERLING: "I do not have an answer for that - especially about what the future will be like. I think there will continue to be incremental improvement, but it will not necessarily be unidirectional. I think that at the moment in the States we are in a time of tremendous pushback against all the change that has in fact occurred. And there are areas where ground is being lost that I would never have imagined would ever be lost! For example, there is now a vocal political movement against birth control. Birth control was something that women won in the 20s! And we thought that we would never go back! The fact that there is even a space where people can get public attention to argue that birth control is a bad thing is definitely a step back. At the moment, there is a tremendous pushback against women's clinics and health care for women, and it is all under the umbrella of anti-abortion, but it is much more than anti-abortion. So, we are reliving battles that we thought were won. I do not think we will go back to an era where birth control is illegal, which it was when I was young, but the fact that it is even on the table again is astounding to me. This is the kind of pushback we get, and we have to push back against the pushback. It is this movement of two steps forward and one step back. I could not have predicted what I consider a dark political period for the US, and it makes me very weary of making predictions. I think there are large social forces that I do not understand well enough to know when they are going to come rising out and go 'Enough!' So, we just have to keep pushing for what we believe the progressive things are even though there will always be a lot of unknowns out there. Societal dynamics cannot always be predicted. For example, the event in Missouri this summer where a young Black man was shot and killed by police exploded into an entire mass movement, which is still going on. It was the Ferguson case. So, there are things that happen during political change that are not predictable - both for good and for bad." 


\section{A Feminist Paradise?}

LODAHL: "Do you think that there will be something like a post-revolutionary society where we can say, 'Now it is done, let us just sit back and enjoy'?"

NELSON: "No. You asked when we will get 'there.' The truth is we are never 'there.' We are always 'here.' There is a Buddhist saying: 'Wherever you go, there you are' - you never get 'there.' That should not be a point of discouragement. It does not mean that you should not work for positive change, but the linear story which assumes that you will get to the pot of gold at the end of the rainbow is actually a quite dangerous narrative. I can illustrate that with an example. We finally elected an African American president, Barack Obama, and then we got the Missouri riots, which led to an unmasking of all the cases about police brutality. This shows that just because we elected an African American president we are not 'there' yet. To assume that we are 'there' is just another binary - then versus now. Think about what I was saying before. We have allowed capitalism to go down its worst possible road by believing that people have no choice but to be opportunistic and selfish in business and the market place. This only holds true if we accept the binary of home versus marketplace or care versus rationality. There are older alternative traditions, which we could draw on, in which we can actually use the market and business to do more than maximize profit. That phrase, maximizing profits, was invented by economists. It was not invented by business people - there are a lot of people who move into business because they want to make good products, because they want to innovate. So, if we can get out of the economistic mode of thinking about profits, then we can think about how businesses, as other institutions, should be serving human good. And let us start from where we are and try and make progress rather than aim for the gold at the end of the rainbow."

LODAHL: "I think that will be the last words, so I hope that everyone got some gasoline for their fire so we can all go out and change the world in each of our different fields. It has been a real pleasure talking to you."

\section{Notes}

1 This interview was made possible by generous funds from the Interacting Minds Centre at Aarhus University, and it was organized by the founder of Gendering in Research, Lea Skewes.

\section{Literature Recommendations}

\section{Anne Fausto-Sterling}

Fausto-Sterling, A. 1992. The Myths of Gender - Biological Theories About Women and Men. New York: Basic Books.

Fausto-Sterling, A. 2000. Sexing the Body - Gender Politics and the Construction of Sexuality. New York: Basic Books.

Fausto-Sterling, A. 2012. Sex/Gender: Biology in a Social World. New York: Routledge.

\section{Julie A. Nelson}

Nelson, J. A. and Ferber, M. A. 1993. Beyond Economic Man: Feminist Theory of Economics. Chicago: University of Chicago Press.

Nelson, J. A. 1996. Feminism, Objectivity, \& Economics. London: Routledge. 
Nelson, J. A. 2017. Gender and Risk-Taking: Economics, Evidence, and Why the Answer Matters. New York: Routledge.

\section{Mads Ananda Lodahl}

Lodahl, M. A. 2018. Upassende Opførsel - 100.000 ord imod den heteroseksuelle verdensorden. Copenhagen: Solidaritet.

Lodahl, M. A. 2012. Queer Jihad - Se den heteroseksuelle verdensorden går i stykker. Copenhagen: Solidaritet. 